\title{
A comparison between the effectiveness of dialectical and cognitive behavioral therapy on the mental health of mother \\ Narges Zamani ${ }^{1}$, Saeed Zamani², Mojtaba Habibi ${ }^{3}$
}

\author{
Journal of Research \& Health \\ Social Development \& Health Promotion \\ Research Center \\ Vol. 9, No.1, Jan \& Feb 2019 \\ Pages: 53- 61 \\ DOI: $10.29252 / j r h .9 .1 .53$ \\ Original Article
}

1. Department of Health Psychology, Young Researchers and Elite Club, Hamedan Branch, Islamic Azad University, Hamedan, Iran

2. Department of Clinical Psychology, Young Researchers and Elite Club, Hamedan Branch, Islamic Azad University, Hamedan, Iran

3. Correspondence to: Department of Health Psychology, School of Behavioral Sciences and Mental Health (Tehran Institute of Psychiatry), Iran University of Medical Sciences, Tehran, Iran

Email: Habibi.m@iums.ac.ir

Received: 9 Dec 2014

Accepted: 28 Jan 2015

How to cite this article: Zamani N, Zamani S, Habibi M. A comparison between the effectiveness of dialectical and cognitive behavioral therapy on the mental health of mother. J Research \& Health2019; 9(1): 53- 61 .

\section{Introduction}

People, in general, have different stress tolerance thresholds. When the tension is more than the tolerance level, mental and emotional disorders will be inevitable [1]. One of the significant stressors is having children with disabilities. This may have long-tern effects on the family and can endanger the bases of the family [2].

When a child is added to the family, drastic changes happen in the couple's life that can affect their mental health. In the process of compatibility with changes, parents face with high levels of stress. Sometimes couples experience heightened stress, negative changes in self- esteem and communication, and more conflicts. But, the addition of a child does not necessarily damage the family [3]. Although having children brings the feelings of joy, pride, and personal growth to the mother, it is accompanied by certain challenges and therefore it can be considered as a stressor [3]. Such challenges can lead to negative consequences, as unadjusted parents experience higher levels of anxiety and depression, compared to childless couples [4]. The mothers of children with physical and mental disabilities also suffer from greater stress and anxiety. Some studies have found a positive relationship between the level of parenting stress and the intensity 
of the disability, as well as the type of the problem [5]. In our society, mothers are more involved in their children's affair than fathers; so they communicate more with their children. Moreover, stressful mothers, compared to lowstress mothers, encourage less social skills in their children regarding their interactions with their peers [6]. Stress also makes parents more critical, more reproaching, and more irritable. This in turn increases the symptoms of conduct disorders [7], oppositional defiant disorder, antisocial behavior, and attention deficit hyperactivity disorder [8] among children. Women are exposed to two categories of considerable stressors; the biological identity related stress and the professional responsibility related stress. Reproduction itself is a trigger for stress symptoms [9], while occupational and housework responsibilities including taking care of the elderly, children, and children with special needs, are the other sources of stress in women [10]. Therefore, the mothers of disabled children face with higher levels of stress than mothers with healthy children and their stress affects their parenting abilities which may have negative consequences for the children [11].

A main question is whether mothers' mental health and existence of issues such as depression, anxiety, and stress is related to the intensity of the problems in the children. Considering that some disabilities are more intense than others, some researches take measures in accordance with the development level [12] or the frequency of the disorders and behavioral problems [13] among children. Other researches were focused on the parents' understanding of their child's circumstances, regardless of the parenting stress that is involved to show that the level of parenting stress has a significant relationship with the intensity of the child's disability [14]. Some researches focused on behavior disorders, developmental disorders, and particular disorders such as the fragile X syndrome. By comparing the level of stress in parents of children with attention deficiency hyperactivity disorder, cerebral palsy, developmental disabilities, HIV, and asthma, Gupta [15] we can conclude that parents with children whose disability is accompanied by more behavioral symptoms, experience higher levels of stress. As a result, one can infer that by studying and comparing the stress level in parents of children with special needs, the priorities of the interventions will be determined. Besides, by carrying out stress-management interventions, numerous parenting issues can be prevented.

Anxiety is another factor that emerges as a result of high levels of stress [16]. The presence of a child with special needs causes physical and mental tension and stress for the family, especially for the mother. Parents who have children with developmental disabilities suffer from high level of stress [17] and experience mental disorders, low levels of self-esteem, feeling of guilt, physical dysfunction, and exhaustion [18]. The mothers of children with disabilities report higher levels of anxiety and stress compared to fathers of such children that's since mothers are more involved with their children's issues and undergo more pressure [19]. Mothers, who have children with intense physical disabilities, also reported physical problems [16].

Moreover, depression is one of the most common mental disorders and its prevalence among women has been estimated between $7-21 \%$ [20]. Researches have shown a positive relationship between negative stress and the emergence of the depression. Between 20$50 \%$ of people who experience high levels of stress eventually develop depression as well [21]. The prevalence of depression in mothers who have children with developmental disorders is higher than that among mothers with non-disabled children [22]. Behavior disorders in children are a greater source of stress for mothers compared with the child's disability [23]. Depression usually begins when drastic changes occur in people life and obliges them to leave behind important people or matters in life, such as working or living place [24].

About $15 \%$ of people suffering from major depression commit suicide [25]. The longterm effects of children's disabilities on the 
family life, increases the probability of suicidal thoughts and actions. To our knowledge previously no study was carried out on the life quality of these mothers in Iran. Therefore, this research seems necessary to determine the damage and probable damaged areas for taking appropriate measures for this group of people. Therefore, this study was carried out to compare the effectiveness of dialectical behavior therapy and cognitive behavioral therapy on the mental health, i.e. subscales of depression, anxiety, and stress, in mothers of children with disabilities such as cerebral palsy, autism, and intellectual disability.

\section{Method}

This semi-experimental study was a pretestposttest design with a control group. The study population was consisted of mothers of children with cerebral palsy, autism, and intellectual disability admitted to the rehabilitation center for persons with physical and mental disabilities in Hamedan. Children were between 4-9 years old and were categorized in three groups based on a physician's diagnosis. They received occupational therapy, physiotherapy, and speech-therapy according to their needs. A group meeting was held with the mothers to evaluate the objectives, and a test was given to the mothers who were willing to participate in the current research. Qualified mothers (those acquiring 1 standard deviation above the mean score), were chosen as the sample of the study. 24 mothers whom children were suffering from cerebral palsy, autism, and intellectual disability was selected. Seven mothers of children with cerebral palsy, six mothers of children with autism, and 6 mothers of children with intellectual disability left the study. 19 mothers were assigned to three groups of dialectical behavior therapy (consisting of 7 members: 3 mothers of children with cerebral palsy, 2 mothers of children with autism and 2 mothers of children with intellectual disability), cognitive behavioral therapy (consisting of 6 members: 2 mothers of children with cerebral palsy, 2 mothers of children with autism, and 2 mothers of children with intellectual disability), and the control group (consisting of 6 members: 2 mothers of children with cerebral palsy, 2 mothers of children with autism, and 2 mothers of children with intellectual disability).

Inclusion criteria were: 1) Diagnosis of cerebral palsy, autism, and intellectual disability in the children; 2) Education level of at least primary school; 3) age range of 17-38; 4) Not receiving any simultaneous cognitive therapy aimed at depression, anxiety, and stress disorders; 5) Mothers having (other) healthy children; 6) Families being under protection of State Welfare Organization of Iran; 7) Having children between 4-9 years diagnosed with cerebral palsy, autism, and intellectual disability by a physician.

By the participants' consent, mothers with the above mentioned conditions were evaluated by the Depression Anxiety Stress Scales (DASS).

Exclusion criteria were: 1) Mothers having more than one child with special needs; 2) widowed or divorced mothers; 3) Out-ofhome working mothers; 4) Mothers receiving therapy; 5) Mothers as the head of households; 6) Mothers with no other children.

Procedure include the pretest scores were collected two weeks after the New Year holidays and the intervention included8 sessions (during two months) for therapy groups as dialectical behavior therapy or cognitive behavioral therapy groups. Sessions were held once a week, each lasting from 2 to 2.30 hours. In the case of absence, participants were trained in private. The posttest results were collected after finishing the intervention sessions.

The dialectical behavior therapy design was based on McKay, Wood, and Brantley's work that is scheduled according to Linehan's skilltraining book [26]. For each skill, two group sessions were held by a trained psychologist. Dialectical behavior therapy was invented based on a humanistic and sympathetic attitude, by Marsha Linehan. Linehan's compassionate and "motherly" position in dialectical behavior therapy is too similar to Jeffrey Young's person centered and 
humanistic approach in schema therapy. As a matter of fact, dialectical behavior therapy is a modification of cognitive behavioral therapy. One of the main conveying messages the dialectical behavior therapy to the clients is the stressful life events which is the source of their suffering, not the distortion of the usual stressful events [27]. The participants in dialectical group therapy were allowed to make telephone contacts with the therapist until the end of the sessions in the case of crisis and the therapist would help them use the learned skills in a limited time (between 1 to 10 minutes).

Since this therapeutic method was used for mothers with mood disorders and emotional pain who facing with difficult and bothersome emotions as the negative result of children damages and neglect, the therapy began by training acceptance strategies, i.e. distress tolerance and core mindfulness skills, which are the heart of dialectical behavior therapy [28]. The participants also were taught change strategies i.e. emotion regulation and interpersonal effectiveness skills.

The cognitive behavioral therapy was based on Greenberger and Padesky's work [29] which has always proved to be effective in treating depression, stress, phobias, anxiety, anger, and interpersonal issues.

Each session consisted of two parts: Skill training and homework. The contents of each session are displayed in Table 1.

Table 1 Therapeutic efforts during the sessions

\begin{tabular}{|c|c|c|c|}
\hline Sessions timing & Dialectical behavior therapy & $\begin{array}{c}\text { Cognitive } \\
\text { behavioral therapy }\end{array}$ & $\begin{array}{l}\text { Control } \\
\text { group }\end{array}$ \\
\hline $\begin{array}{l}\text { Week one and two } \\
\text { (Sessions } 1 \text { and } 2 \text { ) }\end{array}$ & $\begin{array}{l}\text { Basic distress tolerance skills (distraction } \\
\text { strategies) } \\
\text { Advanced distress tolerance skills (use } \\
\text { of the present time, self-verbalization, } \\
\text { development of new coping strategies) }\end{array}$ & $\begin{array}{l}\text { Identification } \\
\text { of the cognitive } \\
\text { behavioral Chain }\end{array}$ & $\begin{array}{l}\text { Group } \\
\text { meeting }\end{array}$ \\
\hline \multirow[t]{2}{*}{$\begin{array}{l}\text { Week three and four } \\
\text { (Sessions } 3 \text { and } 4 \text { ) }\end{array}$} & $\begin{array}{l}\text { Advanced core mindfulness skills (logical } \\
\text { mind and intuition) }\end{array}$ & \multirow[t]{2}{*}{$\begin{array}{c}\text { Resisting stress } \\
\text { and negative } \\
\text { thoughts }\end{array}$} & \multirow[t]{2}{*}{$\begin{array}{l}\text { Group } \\
\text { meeting }\end{array}$} \\
\hline & Development of core mindfulness skills & & \\
\hline $\begin{array}{l}\text { Week five and six } \\
\text { (Sessions } 5 \text { and } 6 \text { ) }\end{array}$ & $\begin{array}{c}\text { Basic emotion regulation skills } \\
\text { (identification of the distressing emotions) } \\
\text { Advanced emotion regulation skills } \\
\text { (problem-solving ) }\end{array}$ & $\begin{array}{l}\text { Resisting anxiety } \\
\text { and depression }\end{array}$ & $\begin{array}{l}\text { Group } \\
\text { meeting }\end{array}$ \\
\hline $\begin{array}{c}\text { Week seven and } \\
\text { eight } \\
\text { (Sessions } 7 \text { and 8) }\end{array}$ & $\begin{array}{l}\text { Basic interpersonal effectiveness skills } \\
\text { (balancing wants and "must's) } \\
\text { Advanced interpersonal effectiveness skills } \\
\text { (negotiation skills and interpersonal problem } \\
\text { analysis) }\end{array}$ & $\begin{array}{c}\text { Anger } \\
\text { management and } \\
\text { negative mood } \\
\text { regulation }\end{array}$ & $\begin{array}{l}\text { Group } \\
\text { meeting }\end{array}$ \\
\hline
\end{tabular}

The Depression Anxiety Stress Scales (DASS) is made up of 3 self-report scales for measuring negative emotional symptoms in depression, anxiety, and stress [30]. Antony et al [31] performed a factor analysis on the abovementioned scale and their results showed that the alpha coefficient for depression, anxiety, and stress were relatively $92.97,0.0$, and 0.95 . Correlation calculations in Antony et al study [31] revealed that the correlation coefficient of 0.48 between depression and stress, 0.53 between anxiety and stress, and 0.28 between anxiety and depression exists. The questionnaire's validity and reliability were examined by Samani and Jokar [32] in Iran, and the testretest reliability for measures of depression, anxiety, and stress were respectively $0.80,0.76$, and 0.77. Besides, the Cronbach's alpha for the measures of depression, anxiety, and stress was reported $74.81,0.0$, and 0.78 respectively. Each 
subscale of the test consisted of 7 items, the final score of which was calculated from the sum of the relevant items.

As each participant had one pretest and one posttest score, data was analyzed by using the multivariate analysis of covariance (MANCOVA) with one independent variable (for experimental and control groups), the auxiliary variable of the pretest, and the dependent variable of the posttest in subscales of depression, anxiety, and stress. Data analysis was done using SPSS-22

\section{Results}

Descriptive statistics methods such as the chi-squared test and one-way ANOVA were used to compare the demographic data of the groups which are presented in Tables 2 and 3.

\begin{tabular}{|c|c|c|c|c|c|c|c|c|c|}
\hline \multicolumn{2}{|c|}{$\begin{array}{l}\text { Experimental group } \\
\text { variable }\end{array}$} & \multicolumn{2}{|c|}{$\begin{array}{c}\text { Dialectical } \\
\text { behavior } \\
\text { therapy }\end{array}$} & \multicolumn{2}{|c|}{$\begin{array}{c}\text { Cognitive } \\
\text { behavioral } \\
\text { therapy }\end{array}$} & \multicolumn{2}{|c|}{ Control } & \multicolumn{2}{|c|}{$\begin{array}{l}\text { Chi-squared } \\
\text { comparison }\end{array}$} \\
\hline & & $\mathrm{F}^{*}$ & $\mathrm{P} * *$ & $\mathrm{~F}^{*}$ & $\mathrm{P} * *$ & $\mathrm{~F}^{*}$ & $\mathrm{P} * *$ & $x^{2}$ & $\mathrm{p}$ \\
\hline \multirow{3}{*}{$\begin{array}{l}\text { Experimental } \\
\text { group }\end{array}$} & Cerebral palsy & 3 & 42.85 & 2 & 28.57 & 2 & 28.57 & \multirow{3}{*}{1.02} & \multirow{3}{*}{0.44} \\
\hline & Autism & 2 & 28.57 & 2 & 28.57 & 2 & 28.57 & & \\
\hline & Intellectual disability & 2 & 28.57 & 2 & 28.57 & 2 & 28.57 & & \\
\hline \multirow{5}{*}{$\begin{array}{l}\text { Education } \\
\text { level }\end{array}$} & Primary school & 3 & 42.85 & 1 & 16.66 & 2 & 33.34 & \multirow{5}{*}{4.57} & \multirow{5}{*}{0.60} \\
\hline & Junior high school & 2 & 28.57 & 0 & 0 & 2 & 33.34 & & \\
\hline & High school diploma & 1 & 14.24 & 2 & 33.34 & 1 & 16.66 & & \\
\hline & Associated degree & 1 & 14.24 & 1 & 16.66 & 1 & 16.66 & & \\
\hline & Bachelor's degree & 0 & 0 & 2 & 33.34 & 0 & 0 & & \\
\hline \multirow{2}{*}{$\begin{array}{l}\text { Mother's } \\
\text { occupation }\end{array}$} & Carpet-weaver & 4 & 57.15 & 2 & 33.33 & 3 & 50 & \multirow{2}{*}{3.76} & \multirow{2}{*}{0.26} \\
\hline & Housewife & 3 & 42.85 & 4 & 66.67 & 3 & 50 & & \\
\hline \multirow{3}{*}{$\begin{array}{l}\text { Father's } \\
\text { occupation }\end{array}$} & Government employee & 1 & 14.24 & 2 & 33.34 & 1 & 16.66 & \multirow{3}{*}{3.17} & \multirow{3}{*}{0.76} \\
\hline & Self-employed & 4 & 57.15 & 3 & 50 & 3 & 50 & & \\
\hline & Unemployed & 2 & 28.57 & 1 & 16.66 & 2 & 33.34 & & \\
\hline
\end{tabular}

*Frequency
$* *$ Percentage

Table 3 The comparison of age means in the three groups

\begin{tabular}{lccccc}
\hline Group & Age range & Mean & Standard deviation & F & $p$ \\
Dialectical behavior therapy & $19-36$ & 26.29 & 6.237 & & \\
Cognitive behavioral therapy & $17-38$ & 26.83 & 6.047 & 0.51 & 0.78 \\
Control group & $18-38$ & 24.17 & 7.223 & & \\
\hline
\end{tabular}

Table 2 reveals that the highest frequency in education level, i.e. 26.31, belonged to primary school education which is higher for dialectical behavior therapy group. The lowest frequency also belongs to above-diploma groups as the same as the dialectical behavior therapy and control groups. In the case of occupation, housewife mothers had the highest frequency (52.63) and were more in number for the cognitive behavioral therapy group and in regards to fathers' occupation, the highest frequency, which was 52.63 , belonged to self- 
employed fathers.

According to this table, one can infer that there were no significant differences between experimental groups, concerning education level and parents' occupation and therefore, the groups were matched.

The highest and the lowest mean of age belonged to the dialectical behavior therapy and the control groups; respectively 26.86 and 24.17. Thus, there were no significant differences between the participants and they can be considered as matched.
To assess the homogeneity of the intervention and control groups, the multivariate analysis of covariance (MANOVA) was used for random sampling as well as the assignment of the two groups in pretest, regarding the mental health variable. Findings showed no significant difference between the two groups in regards to stress $(p=0.39, F(16,2)=0.99)$, anxiety $(\mathrm{p}=0.13, \mathrm{~F}(16,2)=2.3)$, and depression $(p=0.09, F(16,2)=2.85)$. As a result, the homogeneity of the two groups of intervention and control was evident in pretest.

Table 4 Descriptive statistics in mental health scale in pretest and posttest

\begin{tabular}{llcccccc}
\hline Group & Subscale & $\begin{array}{c}\text { Pretest } \\
\text { mean }\end{array}$ & $\begin{array}{c}\text { Standard } \\
\text { deviation }\end{array}$ & $\begin{array}{c}\text { Posttest } \\
\text { mean }\end{array}$ & $\begin{array}{c}\text { Standard } \\
\text { deviation }\end{array}$ & $\begin{array}{c}\text { Adjusted } \\
\text { mean }\end{array}$ & $\begin{array}{c}\text { Standard } \\
\text { error }\end{array}$ \\
\hline \multirow{2}{*}{$\begin{array}{l}\text { DBT } \\
\text { group }\end{array}$} & Stress & 25.28 & 1.11 & 14.71 & 1.70 & 14.66 & 0.72 \\
& Anxiety & 24.14 & 1.67 & 17.42 & 2.63 & 14.98 & 0.81 \\
& Depression & 27.57 & 0.78 & 13.85 & 1.46 & 23.90 & 0.76 \\
CBT & Stress & 25.66 & 0.81 & 14.83 & 1.32 & 17.45 & 0.77 \\
group & Anxiety & 25.33 & 1.21 & 11.66 & 1.03 & 12.17 & 0.86 \\
& Depression & 26.33 & 1.86 & 18.66 & 1.03 & 22.62 & 0.82 \\
\hline \multirow{2}{*}{$\begin{array}{l}\text { Control } \\
\text { group }\end{array}$} & Stress & 24.33 & 2.65 & 24.00 & 1.67 & 13.72 & 0.53 \\
& Anxiety & 25.66 & 1.03 & 23.16 & 1.16 & 18.73 & 0.60 \\
\hline
\end{tabular}

The analysis of covariance test was used to compare the mental health of mothers in intervention and control groups for the subscales of stress, anxiety, and depression. The Box's M results approved the homogeneity of variancecovariance matrix (F $(1168,12.48)=0.69$, $\mathrm{p}>0.05)$. Levene's homogeneity test showed variance homogeneity for the intervention and control groups in all three subscales of stress $(\mathrm{p}=0.63, \mathrm{~F}(16,2)=0.16)$, anxiety $(\mathrm{p}=0.08$, $\mathrm{F}(16,2)=1.98)$, and depression $(\mathrm{p}=0.47$, $\mathrm{F}(16,2)=0.79)$.

Table 5 MANCOVA results for experimental and control groups in mental health subscales.

\begin{tabular}{lcccc}
\hline Subscale & $\begin{array}{c}\text { Degrees of } \\
\text { freedom }\end{array}$ & F & $\begin{array}{c}\text { Significance } \\
\text { level }\end{array}$ & $\begin{array}{c}\text { Eta } \\
\text { squared }\end{array}$ \\
\hline Stress & $2-13$ & 45.29 & 0.001 & 0.87 \\
Anxiety & $2-13$ & 34.97 & 0.001 & 0.84 \\
Depression & $2-13$ & 121.29 & 0.001 & 0.95 \\
\hline
\end{tabular}

The covariance analysis, by the control of the pretest effect on the posttest showed that regarding the mental health of mothers in the experimental group, there was a significant reduction in the subscales of stress, anxiety, and depression after the dialectical behavior therapy and cognitive behavioral therapy interventions (Table 3).

Bonferroni post-hoc test results revealed that: - There was no significant difference in the stress variable with dialectical behavior therapy and cognitive behavioral therapy, while both groups showed a significant reduction compared to the control group $(p<0.01)$

- There was no significant difference in the anxiety variable with dialectical behavior therapy and cognitive behavioral therapy, while both groups showed a significant reduction compared to the control group $(\mathrm{p}<0.01)$ 
- There was no significant difference in the depression variable with dialectical behavior therapy and cognitive behavioral therapy, while both groups showed a significant reduction compared to the control group $(\mathrm{p}<0.01)$

\section{Discussion}

The comparison between pretest and posttest score showed a drastic reduction in the score of the subscales of stress (pretest: 25.28, posttest: 14.71), anxiety (pretest: 24.14 , posttest: 17.42 ), and depression (pretest: 27.57, posttest: 13.85) after the intervention of dialectical behavior therapy, compared to the control group scores in stress (pretest: 24.33 , posttest: 24.00 ), anxiety (pretest: 25.66, posttest: 23.16), and depression (pretest: 27.83 , posttest: 26.00 ). It demonstrates the effectiveness of the dialectical behavior therapy, which assumes that people lack the required skills for creating a life worth living. As a matter of fact, dialectical behavior therapy is a modified form of cognitive behavioral therapy which is designed to help people suffering from out-of-control emotions and mood and affective disorders such as depression, anxiety, anger, emotional instability, and irritability to change their patterns of behavior. The therapist helps the clients to identify the ineffective behavior and teaches them the acquired problem solving behavior, as the assumption suggests that the clients lack the required skills to react in a creative way. This shows the effectiveness of dialectical behavior therapists' work in reducing mood and affective disorders such as depression, anxiety, and stress. Katz et al. [33], Koons et al. [34], Bohus et al [35], McQuillan et al. [36] and Mazaheri, Borjali, Ahadi, and Golshani [37] who studied the effectiveness of dialectical behavior therapy on reducing impulsive behavior and self-harm, emotion regulation and improvement of mood and affective disorders such as depression, anger, emotional instability, irritability, uncontrollable patterns and inappropriate emotions that lead to depression, anxiety, and stress in patients with intense disorders also support these results. The above-mentioned studies were differed because they were carried out on patients with borderline personality disorder and other intense disorders in which emotion and mood issues are typical features and are among the symptoms of the existing disorders.

According to the studies in this field, it could be concluded that dialectical behavior therapy has been successful due to its role in easing the suffering of those with emotional problems by dialectical behavior therapy skills which reduce unpleasant emotions. The current study studied the effectiveness of dialectical behavior therapy in people whose inability in emotion regulation and mood disorders was not as severe as those with borderline personality disorder, while their emotional pain was higher than the emotional suffering patients in borderline. In absence of emotion regulation skills, depression, anxiety and stress increase. Behavior therapy was effective on non-borderline patients in this study because its core mindfulness, interpersonal effectiveness, and distress tolerance training which alienated the clients from the past inappropriate emotions to the present time. It should be kept in mind that these people have been violent, aggressive and hostile inside. They were only viewed as pleasant and sociable people because they have aimed their negative feelings towards themselves in a self-destructive manner. Living under a social mask has shaped an underlying anger in these people that exposes itself in the form of unexpected episodes of rage.

It should be noted that the population and the type of the current study brings about limitations in generalizability of the findings, interpretations and etiological attributions of the study variables. To assess the effectiveness of dialectical behavior therapy and cognitive behavioral therapy on depression, anxiety and stress in mothers of children with cerebral palsy, autism, and intellectual disability, further studies are suggested as follows:

1) Studying or following up the effectiveness of dialectical behavior therapy and cognitive behavioral therapy on anxiety, stress, and depression in future studies.

2) Carrying out the mentioned studies by considering the limitations of the current 
study, and in accordance with the applied executive instructions among other families with disabled members.

\section{Conclusion}

From all effective treatments on depression, cognitive behavioral therapy, as introduced by Beck and his colleagues has been one of the most popular and successful approaches. Pharmacology studies showed that a potential need exists for supportive psychotherapy and behavioral interventions in depression after illness (stroke) which is more effective than pharmacotherapy [20]. Initial studies carried out by Taylor and Marshal and also Rush, Beck, and Khatami's single case studies have used cognitive behavioral approaches for treating depression in a controlled way and proved the effectiveness of this treatment. Moreover, Bellini, Wiseman, Lattimore, Ellis, and Tisdale revealed that cognitive behavioral therapy has an immediate and beneficial effect on the mood and emotion [24]. Mental health (lack of anxiety, depression, and stress) is a fundamental concept including all factors applicable for prevention, emergence, or the development of the cognitive, emotional, and behavioral disorders [10]. Among the evaluated psychosocial approaches in treating emotional and behavioral disorders and the improvement of mental health, the cognitive behavioral therapy is highly validated. Studies by Ghodse and Maxwell [38] and Otto, Powers, and Fischmann [39] proved that group cognitive behavioral therapy is effective on treating depression, anxiety, and stress. Therefore, the current study was carried out with the aim of comparing the effectiveness of this approach and dialectical behavior therapy on the mental health of mothers having children with special needs. The results showed that cognitive behavioral therapy was more effective than dialectical behavior therapy in anxiety reduction.

\section{Acknowledgements}

The authors would like to express their gratitude to all the participants and the staff of the State Welfare Organization of Iran.

\section{Contributions}

Study design: NZ

Data collection and analysis: NZ, MH

Manuscript preparation: NZ, SZ

\section{Conflict of Interest}

"The authors declare that they have no competing interests".

\section{Funding}

The author (s) received no financial support for the research, authorship and/or publication of this article.

\section{References}

1- Hakimjavadi M, Lavasani MGH, Haghighatgi M, Zebardast $\mathrm{O}$. The relationship among depression, anxiety, stress, and personality in veteran's children. Iran Journal of Public Health2010; 3(1): 9-16.

2- Sajedi E, Vameghi R, Alizad V, et al. Is anxiety more common in mothers of children with cerebral palsy? Journal of Rehabilitation2011; 11(5): 15-20.

3- Ostberg M. Parental stress, psychosocial problems and responsiveness in help-seeking parents with small (2-45 months old) children. Acta Paediatr1998; 87(1): 69-76.

4- Crnic KA, Greenberg MT. Minor parenting stresses with young children. Child Dev1990; 61(5): 1628-37.

5- Baxter AC, Lotspeich LJ, Spiker D, Martin JL, Grether JK, Hallmayer JF. Brief report: effect of maternal age on severity of autism. J Autism Dev Disord2007; 37(5): 976-82.

6- Bhavnagri NP. Low income African American mothers' parenting stress and instructional strategies to promote peer relationships in preschool children. Early Educ Dev1999; 10(4): 551-71.

7- Webster-Straton C. Stress A potential disruptor of parent perceptions and family of interactions. J Clin Child Psychol1990; 19(4) 302-12

8- Barkley RA. Attention-deficit hyperactive disorder: A handbook for diagnosis and treatment (3nd ed). New York: Guilford; 2006.

9- Khodayarifard M, Parand A. Stress and coping skills in adolescents. Tehran: Tehran university publication; 2007.

10- Keyvanlou F, Koushan M, Seyedahmadi M, Mohammadi Raoof M. Comparing the mental health of athlete and nonathlete university students. Journal of Sabzevar University of Medical Sciences2010; 17(2):116-22.

11- Beck A, Hastings RP, Daley D, Stevenson J. Pro-social behaviour and behaviour problems independently predict maternal stress. J Intellect Dev Disabil2004; 29(4): 339-49. 12- Hanson MJ, Hanline MF. Parenting a child with 
a disability: A longitudinal study of parental stress and adaptation. J Early Interv1990; 14(3): 234-48.

13- Briggs-Gowan MJ, Carter A, Moye Skuban E, McCue Horwitz S. Prevalence of social-emotional and behavioral problems in a community sample of 1-and 2-year-old children. J Am Acad Child Adolesc Psychiatry2001; 40(7): 811-9.

14- Fidler DJ, Hodapp RM, Dykens EM. Stress in families of young children with Down syndrome, Williams syndrome, and Smith-Magenis syndrome. Early Educ Dev2000;11(4):395-406

15- Gupta VB. Comparison of parenting stress in different developmental disabilities. J Dev Phys Disabil2007; 19(4): 417-25.

16- Jordan BK, Marmar CR, Fairbank JA, et Al. Problems in families of male Vietnam veterans with posttraumatic stress disorder. J Consult Clin Psychol1992; 60(6): 916-26.

17- Schieve LA, Blumberg SJ, Rice C, Visser SN, Boyle

C. The relationship between autism and parenting stress. Pediatrics2007; 119 (Suppl 1): 114-21.

18- Hedov G, Annerén G, Wikblad K. Self-perceived health in Swedish parents of children with Down's syndrome. Qual Life Res2000; 9(4): 415-22.

19- Hastings RP. Child behaviour problems and partner mental health as correlates of stress in mothers and fathers of children with autism. J Intellect Disabil Res2003; 47(Pt 4-5): 231-7.

20- Mast BT, Vedrody S. Poststroke depression: a biopsychosocial approach. Curr Psychiatry Rep2006; 8(1): 25-33.

21- Barlow DH, Durand VM. Abnormal psychology: An integrative approach. Belmont, CA, US: Thomson Brooks/ Cole Publishing Co; 1995.

22- Olsson MB, Hwang CP. Depression in mothers and fathers of children with intellectual disability. $J$ Intellect Disabil Res2001; 45(Pt 6): 535-43.

23- Koegel RL1 Schreibman L, Loos LM, et al. Consistent stress profiles in mothers of children with autism. $J$ Autism Dev Disord1992; 22(2): 205-16.

24- Hawton K, Salkovskis PM, Kirk J, Clark DM. Cognitive behaviour therapy for psychiatric problems: A practical guide. New York, NY, US: Oxford University Press; 1989.

25- Halgin RP, Whitborne SK. Abnormal psychology: clinical perspectives on psychological disorders. 4th ed. Boston: McGraw-Hill; 2003.

26- Linehan MM. Diagnosis and treatment of mental disorders. Cognitive-behavioral treatment of borderline personality disorder. New York, NY, US: Guilford press 1993.
27- Linehan MM, Armstrong HE, Suarez A, Allmon D, Heard HL. Cognitive-behavioral treatment of chronically parasuicidal borderline patients. Arch Gen Psychiatry1991; 48(12): 1060-4.

28-Alilo MM, Sharifi MA. Dialectic behavioral therapy for borderlin personality disorder. Tehran: Tehran university publication; 2011.

29- Greenberger D, Padesky CA. Mind over mood: A cognitive therapy treatment manual for clients. New York, NY, US: Guilford press; 1995.

30- Lovibond SH, Lovibond PF. Manual for the depression anxiety stress scale. Sydney: Psychology foundation of Australia; 1995.

31- Antony MM, Bieling PJ, Cox BJ, Enns MW, Swinson RP. Psychometric properties of the 42-item and 21-item versions of the depression anxiety stress scales in clinical groups and a community sample. Psychol Assess 1998 Jun; 10(2): 176.

32- Samani S, Jokar B. A Study on the reliability and validity of the short form of the depression anxiety stress scale (DASS-21). Journal of social sciences and Humanities of Shiraz University2007; 26(3): 65-77.

33- Katz LY, Cox BJ, Gunasekara S, Miller AL. Feasibility of dialectical behavior therapy for suicidal adolescent inpatients. J Am Acad Child Adolesc Psychiatry2004; 43(3): 276-82.

34- Koons CR, Robins CJ, Tweed JL, et al. Efficacy of dialectical behavior therapy in women veterans with borderline personality disorder. Behav Ther2001; 32(2): 371-90.

35- Bohus M, Haaf B, Stiglmayr C, Pohl U, Böhme R, Linehan M. Evaluation of inpatient dialectical-behavioral therapy for borderline personality disorder--a prospective study. Behav Res Ther2000; 38(9):875-87.

36- McQuillan A, Nicastro R, Guenot F, Girard M, Lisser C, Ferrero F. Intensive dialectical behavior therapy for outpatients with borderline personality disorder who are in crisis. Psychiatr Serv2005; 56(2):193-7.

37- Mazaheri M, Borjali A, Ahadi H, Gholshani F. Effectiveness of dialectical behavior therapy in treatment of border line personality disorder. Journal of Psychological Researches2010; 2(5): 1-25.

38- Ghodse H, Maxwell D. Substance abuse and dependence. Basingstoke, UK: Palgrave macmillan; 1990. 39- Otto MW, Powers MB, Fischmann D. Clinical psychology review: outcome research study at one year changes in substance use health and criminal behavior after one year. London: Department of health, preference in rat. Brain Research2005; 965: 212-21.

\footnotetext{
Copyright $@ 2016$ ASP Ins. This open-access article is published under the terms of the Creative Commons Attribution-NonCommercial 4.0 International License which permits Share (copy and redistribute the material in any medium or format) and Adapt (remix, transform, and build upon the material) under the Attribution-NonCommercial terms.
} 